\title{
Effect of Pre-designed Instructions for Mothers of Children with Hypospadias on Postoperative Complications
}

\author{
Sanaa A. Mohamed \\ Lecturer of Pediatric Nursing, Faculty of Nursing, Cairo University
}

\begin{abstract}
Hypospadias is a common congenital anomaly with a high incidence on postoperative complications. So, the purpose of the study was to investigate the effect of pre-designed instructions for mothers of children with hypospadias on postoperative complications. A convenient sample that consists of 60 mothers of children with hypospadias was included in the study. The sample was divided into 2 equal groups; the control group and the study group. Pre-post quasi experimental design was utilized to fulfill the aim of the study. The study was conducted in the pediatric surgical department and urology outpatient clinic at one Pediatric Hospital in Cairo. Three instruments were used to collect data about mothers' knowledge, mothers' practices regarding care of hypospadias, postoperative complications assessment sheet, and predesigned instructions were provided for those mothers preoperatively. The study results revealed that a highly significant statistical difference was present between the control and the study group regarding mothers' knowledge in post-test. The majority of mothers in the control group and the study group had inadequate level of knowledge about hypospadias in pre-test. While more than two fifths of mothers in the study group had adequate level of knowledge in post-test. The results proved that the mothers' practices in post-test were increased more than in pre-test, less than half of the mothers in pre-test were not satisfied about performing diaper care correctly. However in post-test more than three quarters of mothers were performing this procedure correctly, and there were highly statistical significant difference between pre and post-test. Regarding early postoperative complications; the results demonstrated that more than two thirds of children in pre-test, compared to less than two fifth in post-test suffered from postoperative complications such as; infection, urinary tract obstruction and bleeding. The current study concluded that the pre-designed instructions for mothers of children with hypospadias were efficient by means of marked improvement of the knowledge and practices of the study group, which support the research hypotheses. So the results indicated that children with hypospadias were fewer early postoperative complications in the study group than the control group. The study recommended that pre-designed instructions must be provided for mothers of children with hypospadias to reduce postoperative complications. Also a longer follow-up could be necessary to monitor the late post-operative complications.
\end{abstract}

Keywords: Hypospadias, pre-designed instructions, postoperative complications.

\section{INTRODUCTION}

Hypospadias is a common congenital anomaly with a prevalence estimated to be as high as 1 in 125 live male births. Complications of hypospadias surgery are higher than other reconstructive procedures. The incidence of complications can be reduced by meticulous preoperative planning, and judicious postoperative care. Hypospadias occurs when the urethra (the opening where the urine comes out) is on the underside of the penis instead of the tip. Boys with hypospadias urinate in a downward stream rather than out and away from the body. This causes wet clothes and shoes. If not repaired, hypospadias may make future sexual intercourse 


\section{Effect of Pre-designed Instructions for Mothers of Children with Hypospadias on Postoperative Complications}

difficult, and could affect fertility. The operation involves making a new opening on the tip of the penis. If a chordee is present, it will be corrected at the same time. After healing most boys have normal function and appearance of the penis (Coran, Arnold, Scott, Adzick, Kummel, Thomas, Martin, Laberge, Shamberges, Robert, \& Caldamone, 2012).

Complications after surgical procedures are possible and require a proper assessment and decision making for management. Mismanagement can result in failure of the procedure and high rate of complications. The complications rate of hypospadias correction is considerable, from 30 to $50 \%$. Early complications such as: bleeding, bruising, wound dehiscence, flap or graft necrosis, urinary tract infections and urinary tract obstruction (Wilcox, Godbde \& Cooper, 2014). Hypospadias repair requires delicate handling of loose and fragile tissue susceptible to edema and infection. Complications depend on the type of hypospadias, surgical technique, size of the penis, age of the child, and experience of the operating surgeon. In many countries with advanced medical and social development, the actual trend is towards earlier intervention with ever-shorter hospitalization. However, many boys do still have to remain in hospital for considerably longer (Marrocco, Vallaciani, Fiocca \& Calisti, 2014).

Appignani, Prestipino, Bertozzi, Nardi \& Falcone (2009) mentioned that children who don't have a catheter may complain of discomfort or cry while urinating through the repaired area for one or two days. If the child wears a diaper, the catheter will drain into his diaper. If the child is older, the catheter will drain into a bag on his leg. Urine may leak around the tube or spurt through the tube. This is common and is not a problem, as long as most of the urine drains through the tube. Excessive leaking might indicate the tube is blocked. If the mothers suspect this, or if the tube comes out, call Pediatric Urology. The surgery is usually done when the child is between 6 and 12 months of age. Opening is away from the tip of the penis, the higher the chance of problems after surgery (Palmert \& Dahms, 2010). The incidence of hypospadias is increasing in both Europe and North America but the reasons are not yet clearly understood (Wilcox, et al., 2014).

The mother needs instructions about postoperative complications as; it is normal for bruising and swelling to the penis to develop within the first 24 hours. The nurse must advise the mother that the child wears loose fitting clothing to go home in and for the next few days after surgery to help prevent discomfort. Occasionally a dressing is put on over the penis. If bleeding occurs, apply gentle pressure to the incision for 5 minutes. If bleeding does not stop or starts again, call the surgeon. It was recommend that bathe the child once a day and as needed (after bowel movements) in plain water for 5-10 minutes (55Wenli, 55Yuehong, 55Amy, 55Dominic \& 55 Brad , 2012). There may be some soreness or pain in the penis and abdomen (belly). Medicine will be prescribed for pain. The pain is usually worst the first 3 days after surgery (Janson, 2014).

The child may be given a bath on the day of surgery if necessary. However, the mother should discuss this with the surgeon. Some parents have found a bath ring is more comfortable for their baby. Never leave the child alone in the bath. A follow-up visit should be scheduled for four weeks after the tube is removed. And it should include an early evaluation within 3 months of 


\section{Effect of Pre-designed Instructions for Mothers of Children with Hypospadias on Postoperative Complications}

surgery, followed by a review at 1 or 2 years, and again at 4 or 5 years. The quality of maturation should be assessed subjectively, and when possible confirmed objectively with uroflowmetry and perhaps a bladder pre and post-maturation ultrasound evaluation. If the child is toilet trained, the surgeon need to observe him urinating while standing up at his next office visit. Encourage the child to drink on his way to the office so that he will be ready to urinate when you arrive (Leung \& Robson, 2012). Mother's co-operation is crucial specially in young infants and an open system with a dripping stent and double diaper method of diversion will adequately contain the urine drainage and also prevent the child from interfering with the operation site.

A proper preoperative assessment and planning is must for good results and decrease complications. When resuming regular bathing for the child, use tepid water without soap. Don't scrub the area and don't directly wash the penis; just allow the water to soak the area. Gently pat the area dry with a clean towel (Khan, Zic \& Boorman, 2011). There may be a catheter or stent (small plastic tube) in the penis to drain the urine for several days after surgery, and to maintain patency of the urethral canal. Once the catheter is removed, the child will likely have burning with urination the first few times. If this becomes intolerable for the child, or they are unable to urinate at all, call the surgeon (Janson, 2014).

The Institute of Pediatric Urology, (2014) added that children with hypospadias are often discharged within 1 day of surgery. Discharge teaching should include instructions for mothers about: care of the reconstructed area (dressing, stent and prevent adhesions), medications (antibiotics, pain management), hygienic care (bathing, diaper care), diet and activities. Tsiligiri, (2010), stated that preoperative teaching can relieve some of mothers' anxiety about the future appearance and functioning of the penis, and improve postoperative care. Mothers need information about the admission, the procedure itself, possible complications, and both the short and long-term surgical outcomes within individual units (Springer, 2014). They need to know the length of stay and what community support is available at discharge. Providing such information, especially in detail, can be difficult at the initial outpatient consultation. Although information is given to the family when the child is first seen in clinic, often the child is only a few months old.

The mothers should be instructed from the nurse after surgery to double diaper of the baby. If the child wears diapers, use two diapers for added protection and cushioning. If the child is going home with a tube in his penis or bladder, the nurse will show the mother how to arrange the double diapers. The inner diaper is for his bowel movements and the outer diaper will absorb his urine. If the mother notices a dry diaper, call the surgeon. A spot of blood on the diaper is normal. Avoid applying powder or ointments to your son's genital area. This isn't necessary, but doesn't harm the repair. If the child has a loose bowel movement and soils his surgical dressing, clean it with soapy water and a washcloth, gently wiping away from his penis (Manzoni \& Reali, 2013). Temporary urinary diversion is routinely employed after hypospadias repair in children.

A larger diaper over the regular size diaper can provide extra padding. Loose fitting, comfortable clothes (such as sleepers, sweat pants, or gym shorts) will be best after surgery. It helps to use clothes that are one size 


\section{Effect of Pre-designed Instructions for Mothers of Children with Hypospadias on Postoperative Complications}

larger than normal (Badawy \& Fahmy, 2013). The child should rest at home for a few days and should not take part in any sport or sit astride any toys until all the bruising and swelling has resolved. This may take up to six weeks. This help to prevent the wound getting knocked which may lead to bleeding and damage to the hypospadias repair. Quiet play should encourage. Watching television, playing board games or walking the child in a stroller is encouraged. Avoid contact sports, gym, sandboxes, bicycles and straddling toys. Older children should avoid strenuous activities such as wrestling, gymnastics and bike riding for three weeks. There is no need to restrict the activities of infants, except for swimming and rigorous sandbox play (55Wenli, 55Yuehong, 55Amy, 55Dominic \& 55Brad 2012).

Regarding the diet; Kazemi \& Gholizade, (2013) demonstrated that the child can resume a normal diet at home. Encourage fluids as; ice pops, juice, and soup to keep the child's urine clean. Some children may have nausea or vomiting from the anesthesia. Gradually, the child's appetite will return to normal.The mothers should call the surgeon if the plastic dressing slides down toward the base of the penis, or plastic dressing seems too tight, or child pulls the plastic dressing off, or bleeding from the incision that does not stop after 5 minutes of gentle pressure, or problems with the catheter or stent for example; no urine coming out, leaking around tube, tube seems to have moved in or out, tube falls out, pain that is not relieved with the prescribed medicine, vomiting the day after surgery, temperature higher than $102^{\circ} \mathrm{F}$, increasing swelling, redness, or pain in the penis, and cloudy drainage coming from the incision (Toorn, De Jong, De gier, Callewaert, Horst,
Steffens, Hoebeke, Nijman \& Bush, 2013).

\section{Significance of the study}

Throughout scientific examination in pediatric surgical departments at one Pediatric Hospital, in Cairo; it was observed that the number of children with hypospadias was increasing. There were approximately 200 cases diagnosed as hypospadias through the year 2013 (Computer \& Statistics Center, CUSPH, 2014). The researcher was noticed that children with hypospadias undergoing surgical repair were predisposed for numerous early complications due to be deficient of knowledge and insufficient care given by the mothers for their children. Also, mothers required to instructed about importance of preoperative knowledge and practices, and related effects on reducing postoperative complications and children' sexual status. (Center for the Study \& Treatment of Hypospadias, 2013). Unfortunately, in Egypt, there are restricted researches about nursing care of hypospadias in the pediatric nursing field.

\section{Purpose}

The purpose of the study was to investigate the effect of pre-designed instructions for mothers of children with hypospadias on reducing postoperative complications.

\section{Hypotheses}

The study was examining the following research hypotheses:

1) Mothers of children who will receive pre-designed instructions will have higher level of knowledge than mothers who will not receive instructions.

2) Mothers of children who will receive pre-designed instructions will have higher level of practice 


\section{Effect of Pre-designed Instructions for Mothers of Children with Hypospadias on Postoperative Complications}

than mothers who will not receive instructions.

3) Children whose mothers received pre-designed instructions will have fewer complications than children whose mothers did not received instructions.

\section{Methods}

1-Research Design: A pre-post quazi experimental design was utilized to perform the aim of the study.

2-Setting: The study was done in pediatric surgical department and urology outpatient clinic at Cairo University Specialized Pediatric Hospital.

3-Sampling: A convenient sample consists of 60 mothers of children with hypospadias. The sample size was divided into two equal groups: 30 (study group; those mothers of children with hypospadias were exposed to preoperative predesigned instructions), and 30 (control group; those mothers of children with hypospadias were not exposed to preoperative predesigned instructions).

\section{Inclusion Criteria:}

- Children' age: from birth to 6 years.

- The children should be free from other associated or congenital anomalies in order to reduce the risk of infection or pain.

\section{4- Instruments:}

Data were collected for the current study through the following three tools, which were designed by the researcher based on reviewing the necessary literature, and used for both control and study groups as follow:

1) A questionnaire sheet (pre-post test); to assess mothers' knowledge regarding their children with hypospadias, and created of open and closed questions, as well as data related to definition of hypospadias, signs and symptoms, duration of illness, medical data, preoperative care, postoperative care, discover of disease, prognosis, child' activities postoperative, complications of surgery. Also includes sociodemographic characteristics of the studied sample (mothers and their children with hypospadias), as age, gender, educational level, and address (contains 32 questions).

2) Observational checklist (diaper care); it was developed to evaluate mother's practices, and the effect of the predesigned instructions for mothers of children with hypospadias on reducing postoperative complications; it includes 22 items for the control and the study group postoperatively. Each correct item get one score.

3) Postoperative complications assessment sheet; which was examined occurrence of early postoperative complications immediately (1-7 days) after surgical repair for those children.

4) Mothers' pre-designed instructions; that provided for those mothers preoperatively, and focused on the items related to postoperative care required for those children with hypospadias, such as infection prevention, hygiene, feeding, activities, sleeping, and appropriate positioning of those children, handling, wound care, pain, bleeding, fever, and follow-up.

\section{Scoring System:}

A scoring system was developed to evaluate together mothers' knowledge and skills for their children with hypospadias. Every item in knowledge items scored as 2 for (yes), 1 for (no), and 0 for (I don't know)

- Total knowledge score:

- $\quad$ Poor level of knowledge $=0-50$ 


\section{Effect of Pre-designed Instructions for Mothers of Children with Hypospadias on Postoperative Complications}

- Good level of knowledge= 5162

- Excellent level of knowledge= 63-84

- Level of practices was classified into 3 levels \{for diaper care a total (22) score was then reached\}:

- Level $\{1\}$ appropriate: when the score was reach $60 \%$ and more of the total score.

- Level $\{2\}$ moderate: when the score was ranged from $50 \%$ to less than $60 \%$ of the total score.

- Level $\{3\}$ inappropriate: when the score was less than $50 \%$ of the total score.

Approval from the director of Cairo University Specialized Pediatric Hospital and pediatric surgical department were obtained after submitted a litter from the dean of the Nursing College, Cairo University. Data was collected from the study and control groups using the designed instruments. The study group received the pre-designed instructions preoperatively, while the control group was exposed to the routine care of the surgical department. After explaining the purpose of the study in a clear and simple manner to the mothers of children with hypospadias, they were interviewed individually preoperatively to answer the questionnaire sheet (knowledge about the preoperative care for their children with hypospadias), the interview lasted for 20 minutes for each mother. Preposttest was replicated at urology outpatient clinic for both groups after surgical operation (1-7 days) to assess the improvement in mothers' knowledge and practices. After that an observational checklist (diaper care) was measured \{from 1-7 day\} to evaluate the effect of the pre-designed

\section{Ethical Considerations:}

Oral and written approval to share in the study was obtained mothers of children after an explanation was provided about purpose of research and data collection methods. They were informed that anonymity of personal data will be ensured, and they have the right to withdraw at any time.

Validity and Reliability:

For face validity the tool for the study was provided to a panel of five experts to test the content validity. Reliability was measured by using Cronbach's alpha coefficient test to splits all questions on instrument and computes all correlation value for them.

\section{Procedures:}

instructions for both groups (study \& control). Then the early postoperative complications were assessed immediately (1-7 days) postoperatively by assessment sheet. All questions raised by the mothers about the illness and post-operative care were answered. Discussions of concerned issues were also allowed. Posters and brochures were prepared by the researcher and used for clarification. Data were collected over a period of six months, started from July to December 2013. During this period, the researcher stayed 2 hours daily for 2 days weekly

\section{Statistical Analysis:}

Data were analyzed using Statistical Package for Social Science (SPSS windows) version 20. Numerical data were expressed as mean $\pm \mathrm{SD}$, and range. Qualitative data were expressed as frequency and percentage. Relations between different numerical variables were tested using Pearson correlation. Probability ( $p$-value) less than 0.05 was considered significant and less than 0.001 was considered as highly significant. Statistics used such as t-tests, chi-square test, analysis of 


\section{Effect of Pre-designed Instructions for Mothers of Children with Hypospadias on Postoperative Complications}

variance (ANOVA), and test of correlation (r-test) used to test the research hypotheses and investigate the differences in the mothers' demographic characteristics between the study and control groups. The research hypotheses are tested at alpha level of 0.05 is significance and analyzed the data by using SPSS computer application for statistical analysis.

\section{Results}

Table (1): Distribution of the children in the control and the study group according to their age and numbers of siblings.

\begin{tabular}{|c|c|c|c|c|}
\hline \multirow[t]{2}{*}{ Characteristics } & \multicolumn{2}{|c|}{ Control } & \multicolumn{2}{|c|}{ Study } \\
\hline & No. & $\%$ & No. & $\%$ \\
\hline $\begin{array}{ll}\text { Age in years; } \\
\text { - } & \text { Less than one year } \\
\text { - } & <4 \\
\text { - } & 4-6\end{array}$ & 27 & $\begin{array}{c}6.7 \\
90.0 \\
3.3\end{array}$ & $\begin{array}{c}4 \\
26 \\
0\end{array}$ & $\begin{array}{c}13.3 \\
86.7 \\
0.0\end{array}$ \\
\hline Mean \pm SD & \multicolumn{2}{|c|}{$2.56 \pm 0.79$} & \multicolumn{2}{|c|}{$2.67 \pm 0.98$} \\
\hline $\begin{array}{cc}\text { No. of siblings; } \\
\text { - } & 1 \\
\text { - } & 2 \\
\text { - } & 3 \\
\text { - } & 4 \\
\text { - } & 5\end{array}$ & $\begin{array}{l}8 \\
6 \\
8 \\
5 \\
3\end{array}$ & $\begin{array}{l}26.6 \\
20.0 \\
26.7 \\
16.7 \\
10.0\end{array}$ & $\begin{array}{c}6 \\
7 \\
10 \\
4 \\
3\end{array}$ & $\begin{array}{c}20 \\
23.3 \\
33.4 \\
13.3 \\
10\end{array}$ \\
\hline
\end{tabular}

Table (1) showed that the majority of children in the control group and in the study group $(90 \% \& 86.7 \%)$ ranged between one year and less than 4 years. Moreover, one quarter of children in the control group $(26.7 \%)$ have 1 and 3 siblings in their family. Also in the study group $(33.4 \%)$ have 3 siblings in their family

Table (2): Distribution of the parents in the control and the study group according to their age.

\begin{tabular}{|c|c|c|c|c|c|}
\hline \multirow{2}{*}{\multicolumn{2}{|c|}{ Socio-demographic items }} & \multicolumn{2}{|c|}{ Control } & \multicolumn{2}{|c|}{ Study } \\
\hline & & No & $\%$ & No & $\%$ \\
\hline \multirow{3}{*}{$\begin{array}{l}\text { Fathers' age by } \\
\text { years }\end{array}$} & $25-$ & 16 & 53.3 & 14 & 46.7 \\
\hline & $35-$ & 12 & 40.0 & 13 & 43.3 \\
\hline & $45-$ & 2 & 6.7 & 3 & 10 \\
\hline \multicolumn{2}{|l|}{ Mean \pm SD } & \multicolumn{2}{|c|}{$32.06 \pm 4.44$} & \multicolumn{2}{|c|}{$31.87 \pm 5.01$} \\
\hline \multirow{3}{*}{$\begin{array}{l}\text { Mothers' age by } \\
\text { years }\end{array}$} & $20-$ & 11 & 36.7 & 13 & 43.3 \\
\hline & $30-$ & 18 & 60.0 & 15 & 50 \\
\hline & $40-$ & 1 & 3.3 & 2 & 6.7 \\
\hline Mean \pm SD & $37.5 \pm 4.96$ & 5.11 & & & \\
\hline
\end{tabular}

Table (2) revealed that more than half $(53.3 \%)$ of children in the control group and more than two fifth $(46.7 \%)$ of children in the study group their fathers were aged between 25 years and less than 35 years, with mean and standard deviation $(32.06 \pm 4.44) \&$ (31.87 \pm 5.01$)$ respectively. Furthermore, this table included that near two thirds of children in the control group (60\%), and half (50\%) of children in the study group their mothers were aged from 30 years to less than 40 years with mean age and standard deviation (37.5 \pm 4.96$)$ $\&(36.89 \pm 5.11)$ respectively. Generally, there were no statistically significant differences between the control and the study group in relation to fathers' age and mothers' age.

Table (3): Distribution of the studied sample in relation to parents' education. 


\section{Effect of Pre-designed Instructions for Mothers of Children with Hypospadias on Postoperative Complications}

\begin{tabular}{|c|c|c|c|c|c|}
\hline \multirow{2}{*}{\multicolumn{2}{|c|}{ Socio-demographic items }} & \multicolumn{2}{|c|}{ Control } & \multicolumn{2}{|c|}{ Study } \\
\hline & & & $\%$ & & $\%$ \\
\hline \multirow{6}{*}{$\begin{array}{l}\text { Father's } \\
\text { education }\end{array}$} & Illiterate & 11 & 36.7 & 9 & 30.0 \\
\hline & Can read and write & 4 & 13.3 & 6 & 20.0 \\
\hline & Primary education & 8 & 26.7 & 7 & 23.3 \\
\hline & Preparatory education & 1 & 3.3 & 2 & 6.7 \\
\hline & Secondary school & 5 & 16.7 & 4 & 13.3 \\
\hline & University education & 1 & 3.3 & 2 & 6.7 \\
\hline \multirow{6}{*}{$\begin{array}{l}\text { Mother's } \\
\text { education }\end{array}$} & Illiterate & 9 & 30.0 & \multicolumn{2}{|c|}{33.4} \\
\hline & Can read and write & 4 & 13.3 & 3 & 10.0 \\
\hline & Primary education & 6 & 20.0 & 7 & 23.3 \\
\hline & Preparatory education & 4 & 13.3 & 5 & 16.7 \\
\hline & Secondary school & 6 & 20.0 & 4 & 13.3 \\
\hline & University education & 1 & 3.3 & 1 & 3.3 \\
\hline
\end{tabular}

As showed in table (3) more than one third and less than one third $(36.7 \% \& 30.0 \%)$ of fathers of children with hypospadias in the control group and in the study group were illiterate respectively, in addition to only $(3.3 \% \& 6.7 \%)$ of them were both preparatory and university education in the control group and in the study group respectively. In relation to mothers' education, the results showed that $(30 \% \& 33.4 \%)$ of them in the control group and in the study group respectively were illiterate, and only (3.3\%) were university educated in both groups. In general, there were no statistically significant differences between the control and the study group in relation to fathers' education and mothers' education

Table (4): Distribution of caring person for children in the control and the study group.

\begin{tabular}{|c|c|c|c|c|c|}
\hline \multirow{2}{*}{\multicolumn{2}{|c|}{ Socio-demographic items }} & \multicolumn{2}{|c|}{ Control } & \multicolumn{2}{|c|}{ Study } \\
\hline & & & $\%$ & & $\%$ \\
\hline \multirow{3}{*}{$\begin{array}{l}\text { Caring person } \\
\text { for the child }\end{array}$} & Father & 0 & 0.0 & 1 & 3.3 \\
\hline & Mother & 28 & 93.3 & 26 & 86.7 \\
\hline & Sister/brother & 2 & 6.7 & 3 & 10 \\
\hline \multirow{2}{*}{$\begin{array}{l}\text { Accompanied } \\
\text { person during } \\
\text { child follow up }\end{array}$} & Mother & 28 & 93.3 & 30 & 100 \\
\hline & Father & 2 & 6.7 & 0 & 0.0 \\
\hline
\end{tabular}

As revealed in table (4) that the majority of children in the control group and in the study group $(93.3 \%$ \& $86.7 \%)$ respectively; their mothers were the caring persons for them. In relation to accompanied person during the child follow up in the out-patient clinic; the majority of mothers in the control group, and all in the study group $(93.3 \% \quad \& 100 \%)$ respectively those mothers were accompanied person for their children

Table (5): Distribution of the children in the control and the study group in relation to medical history.

\begin{tabular}{|c|c|c|c|c|}
\hline \multirow[t]{3}{*}{ Medical history } & \multicolumn{2}{|c|}{ Control } & \multicolumn{2}{|c|}{ Study } \\
\hline & Yes & No & Yes & No \\
\hline & No. $\%$ & No. $\%$ & No. & No. \\
\hline Pervious hospital admission & $\begin{array}{ll}3 & 10.0 \\
\end{array}$ & $27 \quad 90.0$ & 0.0 & $\begin{array}{ll}30 & 100.0 \\
\end{array}$ \\
\hline Having any medical disorders & $\begin{array}{ll}5 & 16.7 \\
\end{array}$ & $\begin{array}{ll}25 & 83.3 \\
\end{array}$ & 6.7 & $\begin{array}{ll}28 & 93.3 \\
\end{array}$ \\
\hline Having surgical operation & $\begin{array}{ll}3 & 10.0 \\
\end{array}$ & $27 \quad 90.0$ & 13.3 & $26 \quad 86.7$ \\
\hline Accidents & $6 \quad 20.0$ & $24 \quad 80.0$ & 3.3 & $29 \quad 96.7$ \\
\hline Taking medication regularly & 6.7 & $28 \quad 93.3$ & 10.0 & $27 \quad 90.0$ \\
\hline Sensitivity & 0.0 & $30 \quad 100.0$ & $\begin{array}{ll}3 & 10.0 \\
\end{array}$ & $27 \quad 90.0$ \\
\hline
\end{tabular}
group have not any pervious medical history 


\section{Effect of Pre-designed Instructions for Mothers of Children with Hypospadias on Postoperative Complications}

Table (6): Correlation between mothers' level of knowledge about the disease and study variables among the study group

\begin{tabular}{|l|c|c|}
\hline \multicolumn{1}{|c|}{ Study variables } & \multicolumn{2}{c|}{ Level of knowledge } \\
\cline { 2 - 3 } & $\mathrm{R}$ & $\mathrm{P}$ \\
\hline Age & 0.005 & 0.981 \\
\hline Place of residence & 0.116 & 0.542 \\
\hline Father age & -0.245 & 0.192 \\
\hline Mother age & -0.250 & 0.182 \\
\hline Father level of education & $0.593^{*}$ & 0.001 \\
\hline Mother level of education & $0.481^{*}$ & 0.007 \\
\hline Parents were relatives & $0.332^{*}$ & 0.043 \\
\hline Family income & -0.228 & 0.226 \\
\hline
\end{tabular}

As showed in table (6) among the study group; there were statically significance correlation between level of knowledge about the disease and father's level of education, mother's level of education, and parents were relatives.

Table (7): Correlation between types of mothers' knowledge about the disease and study variables among the study group.

\begin{tabular}{|l|c|c|c|c|c|c|}
\hline \multirow{2}{*}{\begin{tabular}{c}
\multirow{2}{*}{ Study variables } \\
\cline { 2 - 7 }
\end{tabular}} & \multicolumn{6}{|c|}{ Level of mothers' knowledge about } \\
\cline { 2 - 7 } & \multicolumn{2}{|c|}{\begin{tabular}{c} 
Definition of the disease \\
\cline { 2 - 7 }
\end{tabular}} & $\begin{array}{c}\text { Signs and symptoms of } \\
\text { disease }\end{array}$ & \multicolumn{2}{c|}{ Seeking medical help } \\
\cline { 2 - 7 } & $\mathrm{R}$ & $\mathrm{P}$ & $\mathrm{R}$ & $\mathrm{P}$ & $\mathrm{R}$ & $\mathrm{P}$ \\
\hline Child' age & 0.284 & 0.129 & 0.287 & 0.124 & 0.078 & 0.682 \\
\hline Child' rank & $0.456^{*}$ & 0.011 & -0.144 & 0.448 & 0.114 & 0.547 \\
\hline Place of residence & 0.217 & 0.250 & 0.176 & 0.352 & -0.073 & 0.701 \\
\hline Father age & 0.006 & 0.975 & -0.121 & 0.524 & $-0.643^{* *}$ & 0.000 \\
\hline Mother age & 0.032 & 0.867 & -0.191 & 0.312 & $-0.393^{*}$ & 0.032 \\
\hline Father' level of education & 0.235 & 0.211 & $0.449^{*}$ & 0.013 & 0.081 & 0.669 \\
\hline Mother' level of education & $0.375^{*}$ & 0.041 & $0.385^{*}$ & 0.036 & 0.318 & 0.087 \\
\hline Parents were relatives & $0.371^{*}$ & 0.044 & 0.268 & 0.153 & -0.247 & 0.187 \\
\hline Family income & $-0.407^{*}$ & 0.026 & $-0.386^{*}$ & 0.035 & -0.150 & 0.429 \\
\hline
\end{tabular}

As showed from table (7) among the study group; there were statically significance correlations between mothers' knowledge about definition of the disease in relation to ranking of the child, mother' level of education, parents were relatives, and family income. In addition; the table showed that there were statistical significance correlations between mothers' level of knowledge about signs and symptoms of the disease in relation to fathers' level of education, mothers' level of education and family income. Moreover this table revealed that there were statistical significance correlations between father age, mother age and mothers level of knowledge about seeking medical help for their children with hypospadias.

Table (8): Correlation between types of mothers' knowledge about the disease and study variables among the study group (cont.) 


\section{Effect of Pre-designed Instructions for Mothers of Children with Hypospadias on Postoperative}

Complications

\begin{tabular}{|l|c|c|c|c|c|c|}
\hline \multirow{2}{*}{ Study variables } & \multicolumn{5}{|c|}{ Level of mothers' knowledge about } \\
\cline { 2 - 7 } & \multicolumn{2}{|c|}{$\begin{array}{c}\text { Complications of the } \\
\text { disease }\end{array}$} & \multicolumn{2}{l|}{ Surgical operation } & \multicolumn{2}{l|}{ Post-operative care } \\
\cline { 2 - 7 } & $\mathrm{R}$ & $\mathrm{P}$ & $\mathrm{R}$ & $\mathrm{P}$ & $\mathrm{R}$ & $\mathrm{P}$ \\
\hline Age & 0.033 & 0.861 & 0.007 & 0.971 & 0.108 & 0.571 \\
\hline Ranking & 0.088 & 0.643 & -0.266 & 0.156 & -0.150 & 0.429 \\
\hline Place of residence & -0.004 & 0.984 & -0.021 & 0.913 & -0.083 & 0.664 \\
\hline Father age & -0.272 & 0.146 & 0.040 & 0.835 & -0.083 & 0.661 \\
\hline Mother age & -0.281 & 0.132 & -0.092 & 0.629 & -0.143 & 0.451 \\
\hline Father level of education & $0.783^{* *}$ & 0.000 & $0.581^{* *}$ & 0.001 & -0.042 & 0.825 \\
\hline Mother level of education & $0.565^{* *}$ & 0.001 & $0.686^{* *}$ & 0.000 & -0.258 & 0.168 \\
\hline Parents were relatives & 0.151 & 0.427 & 0.255 & 0.175 & -0.121 & 0.526 \\
\hline Family income & -0.155 & 0.414 & -0.255 & 0.173 & 0.099 & 0.602 \\
\hline
\end{tabular}

Table (8) showed that among the study group; there were statically significance correlations between mothers' knowledge about complications of the disease in relation to fathers' level of education and mothers' level of education. As well; it was clear from this table that there were statistical significance correlations between mothers' level of knowledge about surgical operation in relation to fathers' level of education and mothers' level of education. There are no statistical significance correlations between mothers' level of knowledge about postoperative care and all study variables.

Table (9): Correlation between types of mothers' knowledge about the disease and study variables among the study group (cont'd.).

\begin{tabular}{|l|c|c|c|c|c|c|}
\hline \multirow{2}{*}{ Study variables } & \multicolumn{6}{|c|}{ Level of mothers' knowledge about } \\
\cline { 2 - 7 } & \multicolumn{2}{|c|}{ Wound dressing } & \multicolumn{2}{c|}{$\begin{array}{c}\text { Care for urinary } \\
\text { catheter }\end{array}$} & \multicolumn{2}{c|}{ Follow-up } \\
\cline { 2 - 7 } & $\mathrm{R}$ & $\mathrm{P}$ & $\mathrm{R}$ & $\mathrm{P}$ & $\mathrm{R}$ & $\mathrm{P}$ \\
\hline Age & -.047 & .805 & $.329^{*}$ & .016 & -.288 & .123 \\
\hline Ranking & $.354^{*}$ & .045 & -.225 & .232 & -.159 & .402 \\
\hline Place of residence & .091 & .631 & $.318^{*}$ & .047 & -.180 & .341 \\
\hline Father age & -.140 & .459 & -.094 & .620 & -.087 & .647 \\
\hline Mother age & .048 & .800 & $.942^{*}$ & .014 & -.115 & .544 \\
\hline Father level of education & .093 & .625 & $.801^{*}$ & .048 & -.292 & .118 \\
\hline Mother level of education & .124 & .515 & -.134 & .480 & $.307^{*}$ & .029 \\
\hline Parents were relatives & .149 & .430 & $.371^{*}$ & .043 & .071 & .708 \\
\hline Family income & -.074 & .697 & -.044 & .819 & $.526^{* *}$ & .003 \\
\hline
\end{tabular}

${ }^{*}$ P-Value $>0.05$

** P-Value $>0.01$

As observed in table (9) among the study group; there was a statically significance correlation between mothers' level of knowledge about wound dressing and child ranking. Furthermore, there was statistical significance correlations between mothers' level of knowledge about caring of urinary catheter in relation to age of the child, place of residence, age of the mother, father's level of education, and parents were relatives. The table also revealed that, there were statistical significance correlations between mothers' level of knowledge about importance of follow up in relation to mothers' level of education and family income.

Table (10): Variation among pre and post-test in relation to total mothers' knowledge scores in the study group.

\begin{tabular}{|l|c|c|c|c|}
\hline \multicolumn{1}{|c|}{ Variable } & Pre-test & Post-test & \multirow{2}{*}{ t } & \multirow{2}{*}{ p } \\
\cline { 2 - 3 } & M \pm SD & M \pm SD & & $0.000^{*}$ \\
\hline -Mother's knowledge about hypospadias & $12.84 \pm 1.24$ & $5.37 \pm 0.91$ & 28.59 & $0.000^{*}$ \\
\hline -Mother's knowledge about pre-operative preparation & $19.10 \pm 2.43$ & $25.02 \pm 1.78$ & 11.15 & $0.000^{*}$ \\
\hline - Mother's knowledge about post- operative preparation & $36.24 \pm 3.12$ & $31.98 \pm 1.73$ & 4.45 & 0.73 \\
\hline Total knowledge scores & $68.18 \pm 6.79$ & $62.55 \pm 4.42$ & 5.62 & $0.000^{*}$ \\
\hline
\end{tabular}


Effect of Pre-designed Instructions for Mothers of Children with Hypospadias on Postoperative Complications

${ }^{*} p$-value $<0.05$

Table (10) revealed that there were highly statistically significant differences between pre and post-test in relation to

total knowledge scores of the mothers $(\mathrm{t}=28.59, \quad \mathrm{p}=0.000 ; \mathrm{t}=11.15, \quad \mathrm{p}=0.000$; $\mathrm{t}=4.45, \mathrm{p}=0.000$ respectively).

Table (11): Level of mothers' knowledge in the pre - post test for the control and the study group in percentage distribution.

\begin{tabular}{|l|cc|cc|cc|cc|}
\hline \multirow{2}{*}{$\begin{array}{c}\text { Level of mothers' } \\
\text { knowledge }\end{array}$} & \multicolumn{4}{|c|}{ Control } & \multicolumn{4}{c|}{ Study } \\
\cline { 2 - 10 } & No. $\%$ & \multicolumn{2}{|c|}{ Post } & \multicolumn{2}{c|}{ Pre } & \multicolumn{2}{c|}{ Post } \\
No. $\%$ & No. $\%$ & & \multicolumn{2}{c|}{$\%$} \\
\hline High level & 0 & 0.0 & 0 & 0.0 & 0 & 0.0 & 13 & 43.3 \\
\hline Adequate level & 3 & 10.0 & 4 & 13.3 & 0 & 0.0 & 13 & 43.3 \\
\hline Inadequate level & 27 & 90.0 & 26 & 86.7 & 30 & 100.0 & 4 & 13.4 \\
\hline Total & 30 & 100.0 & 30 & 100.0 & 30 & 100.0 & 30 & 100.0 \\
\hline
\end{tabular}

Table (11) proved that the majority $(90.0 \%)$ of mothers in the control group and all mothers $(100.0 \%)$ in the study group had inadequate level of knowledge about hypospadias in the pre-test. As regards post-test; almost all mothers
(86.7\%) in the control group had inadequate level of knowledge, although the same percentage $(43.3 \%)$ in the study group had high and adequate level of knowledge about hypospadias.

Table (12): Distribution of mother's practices checklist regarding to diaper care in pre and post-test in the study group.

\begin{tabular}{|c|c|c|c|c|c|c|c|c|}
\hline \multirow{2}{*}{ Practices } & \multicolumn{4}{|c|}{ Pre-test } & \multicolumn{4}{|c|}{ Post-test } \\
\hline & Yes & $\%$ & No & $\%$ & Yes & $\%$ & No & $\%$ \\
\hline $\begin{array}{cl}\text { Diaper } & \text { care: } \\
\text { - } & \text { Prepare equipment }\end{array}$ & 8 & 26.7 & 22 & 73.3 & 27 & 90 & 3 & 10 \\
\hline - $\quad$ Hand wash & 11 & 36.7 & 19 & 63.3 & 24 & 80 & 6 & 20 \\
\hline - $\quad$ Remove soiled diaper & 27 & 90 & 3 & 10 & 28 & 93.3 & 2 & 6.7 \\
\hline - $\quad$ Assess penis \& diaper area & 7 & 23.3 & 23 & 76.7 & 26 & 86.7 & 4 & 13.3 \\
\hline $\begin{array}{l}\text { Clean \& dry diaper area and } \\
\text { wound site gently }\end{array}$ & 9 & 30 & 21 & 70 & 27 & 90 & 3 & 10 \\
\hline $\begin{array}{l}\text { Apply ointment or petroleum jelly } \\
\text { on diaper area as order }\end{array}$ & 8 & 26.7 & 22 & 73.3 & 23 & 76.7 & 7 & 23.3 \\
\hline - $\quad$ Put new diaper & 23 & 76.7 & 7 & 23.3 & 28 & 93.3 & 2 & 6.7 \\
\hline - $\quad$ Hand wash & 13 & 43.3 & 17 & 56.7 & 22 & 73.3 & 8 & 26.7 \\
\hline - $\quad$ Recording \& reporting & 4 & 13.3 & 26 & 86.7 & 24 & 80 & 6 & 20 \\
\hline
\end{tabular}

As regards to mothers practices in pre and post-test; table (12) proved that the mother's practices in post-test were increase more than in pre-test; in relation to performing diaper care procedures checklist as; they did hand washing before starting the procedure $(36.7 \%-80 \%$ respectively), assess penis \& diaper area $(23.3 \%$
- $86.7 \%$ respectively), apply ointment or petroleum jelly on diaper area as order (26.7\% - $76.7 \%$ respectively), as regards recording $\&$ reporting $(13.3 \%)$ of mothers did it in the pre-test, while the majority $(80 \%)$ of them did it properly in the posttest . 


\section{Effect of Pre-designed Instructions for Mothers of Children with Hypospadias on Postoperative Complications}

Table (13): Mothers total scores of practices (diaper care) pre and post-test in the study group.

\begin{tabular}{|c|c|c|c|c|c|c|c|c|}
\hline \multirow{3}{*}{ Practices } & \multicolumn{4}{|c|}{ Pre-test } & \multicolumn{4}{|c|}{ Post-test } \\
\hline & \multicolumn{2}{|c|}{ Unsatisfactory } & \multicolumn{2}{|c|}{ Satisfactory } & \multicolumn{2}{|c|}{ Unsatisfactory } & \multicolumn{2}{|c|}{ Satisfactory } \\
\hline & No & $\%$ & No & $\%$ & No & $\%$ & No & $\%$ \\
\hline Diaper care: & 14 & 46.6 & 16 & 53.4 & 7 & 23.3 & 23 & 76.7 \\
\hline $\mathrm{X} \pm \mathrm{SD}$ & \multicolumn{4}{|c|}{$1.67 \pm 1.8$} & \multicolumn{4}{|c|}{$1.76 \pm 0.45$} \\
\hline Test & \multicolumn{4}{|c|}{$t=3$} & $=0.0$ & & & \\
\hline
\end{tabular}

${ }^{*}$ p. value $<0.01$

Table (13) revealed that $(46.6 \%)$ of mothers in pre-test were not satisfied about performing diaper care correctly, however in post-test $76.7 \%$ of those mothers were performed this procedure correctly. There were highly statistical significant difference between pre and post-test $(\mathrm{p}<0.004)$.

Table (14) Distribution of children's early postoperative complications in the study group.

\begin{tabular}{|l|c|c|c|c|c|}
\hline \multirow{2}{*}{ Postoperative complications } & \multicolumn{2}{|c|}{ Pre-test } & \multicolumn{2}{c|}{ Post-test } & \\
\cline { 2 - 6 } & No & \% & No & \% & $\mathbf{X}^{\mathbf{2}}$ \\
\hline - Occurred & 21 & 70 & 11 & 36.7 & \\
\hline - Not occurred & 9 & 30 & 19 & 63.3 & $3.19^{*}$ \\
\hline $\begin{array}{l}\text { Types of complications: } \\
\text { - Infection }\end{array}$ & 8 & 38 & 5 & 45.5 & \\
\hline$\quad$ Urinary tract obstruction & 6 & 28.7 & 2 & 18.2 & \\
\hline$\quad$ Bleeding & 4 & 19 & 0 & 0.0 & \\
\hline$\quad$ Pain in surgical wound & 3 & 14.3 & 4 & 36.3 & \\
\hline
\end{tabular}

Regarding early postoperative complications which were examined from 1-7 days immediate after surgical operation for children with hypospadias in pre and post-test in the study group; (table 14) revealed that more than two thirds $(70 \%)$ of children in pre-test, while less than two fifth $(36.7 \%)$ in post-test suffering from postoperative complications. The difference between pre and post-test was significant $\left(x^{2}=3.19\right.$, p. $\left.<0.01\right)$. Concerning types of immediate postoperative complications, the results indicated that $(28.7 \%)$ of children in pre-test, while $(18.2 \%)$ in post-test had urinary tract obstruction. And $(19 \%)$ of those children in pretest, although no one in post-test had bleeding. Although (45.5\%) of those children in post-test had infection.

\section{Discussion}

Hypospadias surgery remains very challenging, with a significant rate of complications even in the best hands.
The incidence of complications can be reduced by particular preoperative instructions; actually mothers of children with hypospadias need to improve their knowledge and practices to reduce postoperative complications. In relation to demographic data; the results showed that, the majority of children in both groups (the control and the study group) were between 1-4 years, this results is to some extent supported with Appignani, et al., (2009), who studied family caregivers' with hypospadias, and found that the highest percentage of children were in age between 1-6 years. The current results indicated that near two thirds of children in the control group, and half of children in the study group their mothers were aged from 30 - 40 years. These results is consistent with Caroline (2014), who studied children with hypospadias, and reported that high percentage from parents were approximately in the same age.

The study founded that more than one third of parents of children with 


\section{Effect of Pre-designed Instructions for Mothers of Children with Hypospadias on Postoperative Complications}

hypospadias in both groups were illiterate in both groups. Generally, there were no statistically significant differences between the control and the study group in relation to children age, numbers of siblings, parents' age, and parents' education. These results in agreement with Bhat \& Mandal, (2008) study, who reported that there were no differences among the studied sample regarding to children age, parents' age, and parents' education. This could reveal the homogeneity of the social characteristics of the sample in the study and control groups. Also the primary care givers in the study and control groups were mothers.

It was evident from the current study that there were statically significance correlations between mothers' level of education in relation to mothers' knowledge about hypospadias, and family income. These findings were supported

55Massimo, \%xe\%55Delphine, 55999

d\%E9rique"Anne-

Frédérique, 55Pierre-

Yves, 55999d\%E9ric"Frédéric, \& 55Pi erre (2008) who emphasized in his study on management of severe hypospadias, and mentioned that importance of parents' education and related effects on knowledge about the disease. In the same context, the authors found that positive relation among mothers' knowledge about hypospadias and financial status of the family.

Apparently, the current study clarified that there was a statically significance correlation between mothers' knowledge about wound dressing and child ranking. In accordance with Manzoni \& Reali (2013) studies of management of hypospadias, he was agreed with the current study, and who stated that there was a relation between parents' knowledge about wound dressing and child ranking. Furthermore, there were statistical significance correlations between mothers' knowledge about caring of urinary catheter in relation to age of the child and age of the mother. These findings be of the same opinion with Coran, et al., (2012), who founded that there was statistical significance associations between mothers' knowledge in relation to caring of urinary catheter with regard to child' age and mothers' age. Moreover, the current study demonstrated that there were statistical significance correlations between mothers' knowledge about importance of follow up in relation to mothers' level of education. These previous findings are incongruent with Manzoni \& Reali (2013), who reported that there was no statically significance correlation between parents' knowledge about importance of follow up for their children with hypospadias and mothers' level of education.

The current study results explained that there were improvement of mothers' knowledge about hypospadias from low percentage in pre-test to high in post-test, which showed statistically significant difference. This may be due to the fact that improvement that have occurred after the instructions application could be referred to its content, which was developed based on the mothers needs for this knowledge, as well as to its clarity, illustrated with pictures, using simple language, regular replication and discussion to fix this knowledge for mothers in caring of their children with hypospadias. In this respect Kazemi \& Gholizade (2013), study on comparison of distal hypospadias repair in circumcised and uncircumcised patients, and identified that there was statistically significant difference between mothers' knowledge in pre and post program application. As well as these results support the first hypothesis which 


\section{Effect of Pre-designed Instructions for Mothers of Children with Hypospadias on Postoperative Complications}

clarified that mothers of children with hypospadias were preoperatively instructed will have better knowledge than the not instructed mothers.

Noticeably, the current study proved that the mothers' practices in post-test were increased more than in pre-test; in relation to performing diaper care checklist as; assess penis \& diaper area, apply ointment or petroleum jelly on diaper area as order. Mothers in pre-test were not satisfied about performing diaper care correctly, however in post-test; almost of those mothers were performed this procedure correctly. So there were highly statistical significant difference between pre and post-test regarding to mothers practices. The current study was in line with Marrocco, et al., (2014) as they considered that mothers receiving pre designed instructions reported a significant improvement in the daily care difference was detected at 4th and 5th day after surgical repair. As well as, 1Alison, 1Janet \& 1Beverley (2009) who studied improvement in clinical practices and how parents' views their children with hypospadias, and described postoperative nursing management in collaboration with each family following surgery, and clarified that the involvement of parents especially the mothers in decision-making has been at the heart of development in the care of boys who have hypospadias repair, also afford additional benefit of developing a home care and diaper care following hypospadias repair (Michael \& Bruce, 2010). From my point of view; although practical evidence is still awaited, nursing care is vital for the successful pre-, periand post-operative care.

Concerning early postoperative complications for children with hypospadias which were examined immediately (1-7days) after surgical operation in pre and post-test; the study results proved that occurrence of postoperative complications were reduced in post-test $(36.7 \%)$ less than in pre-test in the study group. The difference between pre and post-test was significant. These results were in equivalence with 55Massimo et al., (2008) study on the subject of management of severe hypospadias, and who reported that occurrence of complications were $33 \%$. Furthermore these findings were to some extent supported by (Beuke \& Fisch, 2009) who studies strategies after complications of hypospadias repair, and stated incidence of complications ranged from 6 to 30\%, varying with the severity of the hypospadias. Nuininga, Verschuren, Feitz, Keating, Snodgrass \& Mesrobian, (2011) found that early complications rates in boys with multiple unsuccessful hypospadias repairs of $25.4 \%$. Although; Michael \& Bruce, (2010) who studying hypospadias repairs and paying specific attention to important aspects of nursing care, were including preparing for surgery, and added that; presence of children's departments preadmission clubs to prepare children and their parents for surgery are a part of routine care. Incidence of these complications can be minimized $(<5 \%$ in distal hypospadias and $<10 \%$ in proximal hypospadias) by surgical expertise, preoperative planning, choosing appropriate surgical technique, operating in childhood, using magnification, fine suture material and judicious postoperative management.

Pertaining to types of early postoperative complications, the current results indicated that occurrence of infection were $(45.5 \%)$ in children with hypospadias in posttest. In agreement with Bhat \& Mandal, (2008) study of acute postoperative complications of hypospadias repair, and reported that 


\section{Effect of Pre-designed Instructions for Mothers of Children with Hypospadias on Postoperative Complications}

postoperative cares are of paramount importance in order to minimize the risks of infections and wound dehiscence. 55Massimo et al., (2008), added that it appears essential to keep the penis still during the first healing phase to improve the outcome and reduce the child's discomfort. This results in argument with Ratan, Sen \& Ratan, (2009), who highlighted incidence of infection, and serious sepsis was rare, but mild and localized infection can occur because of compromised vascularity, humidity, high temperature, and proximity to a potentially contaminated area, the incidence of infection was reported very high $(53 \%)$.

As infection is rare in hypospadias repairs. However, if it occurs the results can be disastrous. Therefore, preoperative povidine iodine scrubbing, the use of antibiotic solution during surgery, avoiding haematoma and a traumatic handling of tissue are frequently recommended (Asklund, Jorgensen, Skakkebaek \& Jensen (2010). Bhat \& Mandal, (2008) study at Paediatric Urology, Royal Manchester Children's Hospital, UK, reported that there is no urinary tract obstruction as postoperative complication, this findings was disagreement with the current study, which recorded that $(18.2 \%)$ of children in post-test were suffering from urinary tract obstruction.

In relation to rate of bleeding (19\%) of those children in pre-test, although no one in post-test had bleeding in the current study. This is in conformity with 55\% Ververidis, 55\%Dickson \& $55 \%(\% 22 \mathrm{D} \% 26$ cauthor $=$ true $\% 26$ cauth or_uid $=15963136 \% 22 \mathrm{Gough} \% 20(201$ 0)\%222010HYPERLINK\%20\%22D\% 26cauthor=true $\% 26$ cauthor_uid $=15963$ 136\%22Gough\%20(2010)\%22)"Goug $\mathrm{h}$ (HYPERLINK "2010)\%22Gough\%20(HYPERLINK $\% 20 \% 22 \mathrm{D} \% 26$ cauthor=true $\% 26$ cauth
or_uid=15963136\%22Gough $\% 20(201$ 0)\%222010HYPERLINK\%20\%22D\% 26 cauthor=true $\% 26$ cauthor_uid $=15963$ 136\%22Gough\%20(2010)\%22)"2010 HYPERLINK "2010)\%22Gough\%20(HYPERLINK $\% 20 \% 22 \mathrm{D} \% 26$ cauthor=true \%26cauth or_uid=15963136\%22Gough $\% 20(201$ 0)\%222010HYPERLINK\%20\%22D\% 26cauthor=true\%26cauthor_uid=15963 136\%22Gough\%20(2010)\%22)") study on the subject of nursing intervention in children with hypospadias complications, and stated that bleeding rate was $30 \%$ in the two groups, the difference was significant. Finally, in equivalence with Brouwers, Feitz \& Roelofs, (2011), who confirmed that there was evidence to show children with hypospadias will recover better with less complications, when their mothers have been well informed by pre designed instructions and have good knowledge on hypospadias and how to deal with those children. Moreover these results were supported the second hyposesis; which stated that the mothers of children with hypospadias were preoperatively instructed will have less postoperative complications for their children with hypospadias than not instructed mothers.

\section{Conclusion}

The current study concluded that the pre-designed instructions for mothers of children with hypospadias were efficient by means of marked improvement of knowledge and practices of the study group, which support the research hypotheses. Mothers of those children were preoperatively instructed were less early postoperative complications than not instructed mothers for their children with hypospadias. As well as there were highly statistically significant differences between pre and post-test in the study group in relation 


\section{Effect of Pre-designed Instructions for Mothers of Children with Hypospadias on Postoperative Complications}

to mothers' knowledge about hypospadias, important of preoperative instructions and postoperative care for those children. And almost of the mothers in the post-test in the study group had appropriate level of practices in relation to diaper care.

\section{Recommendations}

The study recommended that:

- Important of preoperative instructions for mothers of children with hypospadias for reducing postoperative complications.

- Follow-up must be done for longer periods of time to monitor complications.

\section{References}

Alison Gormley, 1Janet Fishwick \& 1Beverley Whitnall (2009). Home Dressing Removal Following Hypospadias Repair. International Journal of Urological Nursing. 4 (1).

Appignani A., Prestipino M., Bertozzi M., Nardi N., Falcone F. (2009). Doublecross Flap Protection: New Technique for Coverage of Neourethra in Hypospad. Repair. J Urol. 182: 1521-7.

Asklund C., Jorgensen N., Skakkebaek N.E. \& Jensen T.K. (2010). Increased Frequency of Reproductive Health Problems among Fathers of boys with Hyposp. Hum Repr;22(10):263946.

Badawy H. \& Fahmy A. (2013). Review of Single - Vs multi Stage Repair of Proximal Hypospadias: the Dilemma Continues. Arab Journal of Urology. Available at: www.sciencedirect.com accessed on $2 / 5 / 2014$.

Bhat A., Mandal A.K. (2008). Acute Postoperative Complications of
Hypospadias Repair. Indian Journal of Urology; 24: 241-248.

Brouwers M.M, Feitz W.F. \& Roelofs L.A., (2011). Risk Factors for Hypospadias. Eur J Pediatr;166 (7):671-8.

Caroline Sanders (2014). Improvements in Communication and Clinical Practice, Paediatric Nursing : 16 (2).

Center for the Study \& Treatment of Hypospadias at University of California, San Francisco (2013). Available at: www.ucsf.edu.com accessed in 22/6/2014.

Computer \& Statistics Center, Cairo University Specialized Pediatric Hospital (CUSPH), 2014.

Coran G., Arnold N., Scott N., Adzick D., Kumme M., Thomas T., Martin J., Laberge S., Shamberges C., Robert R. \& Caldamone A. (2012). Pediatric Surgery. (7th ed.), Elsevier. Philadelphia.

Janson B. (2014). Medical Terminology: An Illustration Guide. (7th ed.), Wolters Klumer Health. Lippincott Williams.

Kazemi F.R. \& Gholizade R. (2013). Comparison of Distal Hypospadias Repair in Circumcised Patients and Uncircumcised Patients. Available at: www.hindawi.com accessed in 21/4/2014.

Khan U., Zic R. \& Boorman J. (2011). Waterproofing in Hypospadias: A refinement of Two Stage Reconstruction. Br J Plast Surg,; 54: 528-31.

Kraft K.H., Shukla A.R. \& Canning D.A. (2010). Hypospadias. Urol Clin North Am. 37:167-81.

Landrigan P., Garg A. \& Droller D.B. (2009). Assessing the Effects of Endocrine Disruptors in the National Children's Study.' Environ Health Perspect.; 111 (13):1678-82. 


\section{Effect of Pre-designed Instructions for Mothers of Children with Hypospadias on Postoperative Complications}

Leung A.K. \& Robson W.L. (2012). Hypospadias: An Update. Asian J Androl; 9:16-22.

Manzoni G.A. \& Reali L. (2013). Management of Hypospadias. Journal of Pediatric Surgical Specialties. 7 (3).

Marrocco G., Vallaciani S., Fiocca G., Calisti A. (2014). Hypospadias Surgery: a 10-year Review. Pediatric Surgery International; 20: 200-203.

55Massimo C., \%xe\%55Delphine D., 55999d\%E9rique\%20V"AnneFrédérique V., 55Pierre-Yves M., 55999d\%E9ric\%20H"Frédéric H. \& 55Pierre M. (2008). Management of Severe Hypospadias. Indian J Urol. 24(2): 233-240.

Michael Pfeil \& Bruce Lindsay (2010). Hypospadias Repair: An Overview. International Journal of Urological Nursing. 4 (1). Available at: http://onlinelibrary.wiley.com accessed in 21/4/2014.

Nuininga J.E., De Gier R.P.E., Verschuren R., Feitz W.H.J., Keating M.A., Snodgrass W.\& Mesrobian H. (2011). Long-term Outcome of Different Types of 1Stage Hypospadias Repair. Journal of Urology; 174: 1544-1548.

Palmert M.R. \& Dahms W.T. (2010). Abnormalities of Sexual Differentiation. In: Fanaroff A, Martin RJ, Walsh MC. NeonatalPerinatal Medicine Diseases of the Fetus and Infant. (8th ed.) Philadelphia: Mosby; pp: 1565-6.

Ratan S.K., Sen A., Ratan J., (2009). Pattern of Bacterial Flora in Local Genital Skin and Surgical Wounds in Children Undergoing Hypospadias Repair: A Preliminary Study. Int $\mathbf{J} \quad$ Clin Pract. 2009; 56:349-52.
Springer A. (2014). Assessment of Outcome in Hypospadias Surgery - A Review available at: www.frontiersin.org accessed in 6/5/2014.

Toorn F.V., De Jong T., De gier R., Callewaert P., Horst E., Steffens, M.G., Hoebeke P., Nijman R. \& Bush N. (2013). Introducing the HOPE (Hypospadias Objective Penile Evaluation)-score A validation Study of an Objective Scoring System for Evaluating Cosmetic Appearance in Hypospadias Patients. Journal of Pesiatric Urology :9, 1006_1017.

Tsiligiri M. (2010). Nursing Care and Parents Contribution in the Care of their Children with Hypospadias. International Journal of Caring Sciences. 13, Issue3. Available at: www.inernationaljournalofcarings cienes.org accessed in 9/5/2014.

The Institute of Pediatric Urology (National Institute at New Yourk, 2014) Available at: https://www.cornellurology.com.

$55 \%$ Ververidis $\quad$ M., 55\%Dickson A.P., 55\%Gough D.C. (2010). Nursing Intervention in Children with Hypospadias Complications of Applied Research, BJU Int. ;96(1):135-9.

Wenli Lu., 55Yuehong Tao., 55Amy B., Wisniewski 55Dominic Frimberger \& 55Brad P. Kropp (2012). Different Outcomes of Hypospadias Surgery Between North America, Europe and China: Is Patient Age a Factor. Nephrourol Mon, 4 (4).

Wilcox D., Godbde P. \& Cooper C. (2014). Oceana Therapeutic Limited. Available at: www.pediatricurologybook.com accessed in 26/4/2014. 